\title{
A Aritmética nos Cadernos de Classe do Ensino Primário dos Hornburg (1950-1968)
}

\author{
Arithmetic in the Hornburg Primary School Classbooks (1950-1968)
}

\author{
Alboni Marisa Dudeque Pianovski Vieira \\ alboni@alboni.com \\ Velcidina Rodrigues Chagas Fischer \\ dina_pro@hotmail.com
}

\begin{abstract}
Resumo
$\mathrm{O}$ artigo discute questões que envolvem a escola, os alunos, a aritmética e os cadernos de classe da Escola Municipal de Ensino Fundamental Professor Henrique Heise, localizada em Jaraguá do Sul/SC, no período de 1950 a 1968. Na problematização, questiona-se o que revelam os cadernos de classe dos irmãos Hornburg, alunos da escola, sobre a aritmética do ensino primário. Como objetivos, propõe-se analisar esses cadernos, para compreender a aritmética desenvolvida na escola, bem como discutir sobre os cadernos de classe e as ações de aritmética presentes no contexto da escola. Justifica-se o estudo, tendo em vista que a análise dos cadernos de classe dos Hornburg possibilita perceber a matemática e as relações que se estabeleceram no cotidiano da escola e que envolveram a aritmética nos saberes elementares propostos para os alunos daquela comunidade. A pesquisa fundamenta-se nos pressupostos da história cultural e é de caráter bibliográfico e documental. Como resultado, pode-se mencionar que nas linhas dos cadernos de classe ficaram assinaladas as marcas dos programas de ensino, as concepções de ensino-aprendizagem desenvolvidas na escola, a cultura escolar e as práticas pedagógicas que envolviam a matemática.
\end{abstract}

Palavras-chave: Escola; Aritmética; Cadernos de classe; História cultural.

\begin{abstract}
The article discusses issues involving the school, the students, the arithmetic and the notebooks of Municipal Elementary School Professor Henrique Heise, located in Jaraguá do Sul/SC, in the period from 1950 to 1968. In questioning, the questions that reveal the Hornburg brothers' class notebooks students of the school, on the arithmetic of the elementary school. As objectives, it is proposed to examine these notebooks, to understand arithmetic in school, as well as discuss the class notebooks and arithmetic actions present in the context of the school. The study is justified, considering that the analysis of the schedules of the Hornburg class allows you to understand the mathematics and the relationships that were established in the everyday life of the school and surrounding the arithmetic in the elementary knowledge proposed for students of that community. The research is based on assumptions of cultural history and bibliographic and documentary character. As a result, we can mention that in lines of notebooks were class indicated the marks of curricula the teaching-learning conceptions developed at the school, the school culture and pedagogical practices involving mathematics.
\end{abstract}

Key words: School; Arithmetic; Class notebooks; Cultural history.

\section{Introdução}

Este artigo tem como objeto de estudo a aritmética nos cadernos de classe do ensino primário dos Hornburg, os quais possibilitam analisar a matemática que foi praticada na Escola Municipal de Ensino Fundamental Professor Henrique Heise, localizada no município 
de Jaraguá do Sul/SC, entre os anos 1950-1968.

Os irmãos Hornburg: Hilário, Anélia, Gisela e Delfino, que foram alunos da escola e são os autores dos cadernos de classe pesquisados, faziam parte da comunidade alemã, a qual preservou a cultura e as tradições predominantes na colônia desde a sua formação. "A presença da cultura alemã na colônia é marcada pela própria etnia dos imigrantes" (BLOGOSLAWSKI, 2000, p.48).

O início das escolas nas comunidades alemãs que foram formadas no sul do Brasil ocorreu no final do século XIX e primeiros anos do século XX, antes mesmo da manifestação do governo sobre a criação de escolas para os recém-chegados.

Renk, destaca que:

\begin{abstract}
Chegando no Brasil, os imigrantes, no século XIX, não esperaram a ação do governo para as instalações de escolas para seus filhos. Criaram-nas com características de identificação com o país de origem, ensinando a língua materna e os costumes da Pátria distante. Estas escolas foram construídas e mantidas com o esforço das comunidades étnicas (RENK, 2005, p.102).
\end{abstract}

Os avós dos irmãos Hornburg chegaram da Alemanha no final do século XIX e no início do século XX, com os demais colonizadores, e formaram a comunidade alemã no interior de Jaraguá do Sul/SC. Os imigrantes se instalaram no município de Pomerode e se expandiram até Jaraguá do Sul/SC, originando o bairro Rio da Luz, que tem até os dias de hoje a predominância da cultura alemã e se situa na divisa dos municípios.

No vale ocupado pelos imigrantes alemães, os Hornburg fizeram parte das famílias pioneiras, "como, Dallman, Lemke, Lindermann, Böeder, Döeger, Mathias, Hoffmann, Hornburg etc." (JARAGUÁ DO SUL, 2016, p.02).

Como prioridade, os imigrantes organizaram a escola da comunidade, iniciativa comum nas colônias de imigração, visto que o governo do Brasil não tinha preocupação com a instrução dos estrangeiros. "Os imigrantes alemães que por razões diversas se instalaram em terras catarinenses, fundavam logo a escola da comunidade, já que o governo brasileiro não se preocupava com a formação cultural destes núcleos de população estrangeira" (MONTEIRO,1979, p.6).

$\mathrm{Na}$ sequência, foram sendo organizadas as instituições sociais necessárias para a sobrevivência coletiva, como: escola, igreja, cemitério, sendo nelas preservada a cultura étnica.

Assim, na criação da escola objeto deste estudo, a família Hornburg teve participação ativa na formação do bairro Rio da Luz, conhecido como um pedaço da Alemanha pela cultura e as tradições. 
Situado a sudeste na cidade de Jaraguá do Sul, o bairro do Rio da Luz é a localidade com maior permanência dos traços que, desde sua fundação até meados dos anos 1960, permeavam a cidade. [...] Devido à sua localização, um vale que se estende até a divisa com o município de Pomerode, e distante cerca de $10 \mathrm{Km}$ do centro da cidade, o Rio da Luz preservou suas características rurais e seus hábitos linguísticos, culinários, religiosos e modos de produção (CAMARGO, 2013, p.86)

As primeiras preocupações que os colonizadores manifestaram na colônia foi com a preservação dos valores culturais. Diante disso, criaram um espaço para a religiosidade e organizaram a escola ${ }^{1}$, para que seus filhos pudessem estudar e, com isso, conseguissem vencer os desafios impostos pela sociedade na nova terra.

Foi o que se assistiu nas colônias de imigrantes alemães onde havia um percentual elevado de luteranos durante o século XIX e XX e que se instalaram principalmente nas terras do sul do Brasil. As gerações adultas queriam escolas para que seus filhos tivessem acesso aos fundamentos da fé e também fossem formados para enfrentar as dificuldades da vida num país estranho e de hábitos culturais diferentes (CECCHETTI, SANTOS, 2013, p.7).

Nas colônias, a organização social dos alemães foi coletiva, tanto na construção dos valores religiosos, como nos escolares. Na Escola Municipal Professor Henrique Heise, a religiosidade estava presente, colaborando para que ocorresse a sociabilidade entre os imigrantes.

Segundo os registros nos cadernos do professor Henrique Heise, que é o patrono da escola e nela lecionou de 1920 a 1935, sua fundação ocorreu em 1899, com o nome de "Escola Particular Mista", 5 (JARAGUÁ DO SUL, 2014, p.4). Há controvérsias sobre essa data, no entanto, posto que outros registros encontrados mencionam sua fundação em $1^{\circ}$ de junho de 1915, numa pequena casa de madeira, conhecida como "Escola da Comunidade" (Schulgemeinde) (JARAGUÁ DO SUL, 2014, p.4).

As normatizações que foram incorporadas quando a escola iniciou suas atividades tiveram interferência das instituições sociais, criadas na própria comunidade. As manifestações culturais na religião, na escolarização, nos modos de trabalho, entre outras, estabeleceram os valores e as condutas para os integrantes da colônia.

Sobre essas práticas, Chartier explica que "vale para uma história das práticas, que são elas também, invenções de sentido limitadas pelas múltiplas determinações (sociais, religiosas, institucionais etc.) que definem, para cada comunidade, os comportamentos legítimos e as normas incorporadas" (CHARTIER,1995, p. 190). As finalidades da aritmética foram impostas pela sociedade, que organizou as ações do ensino da matemática que se desenvolveu na escola, de acordo com os interesses de comunidade local.

1 "Preocupados com a educação de seus filhos, buscam dividir as atribuições na dura missão de construir uma escola semelhante as escolas alemãs já existentes em outras colônias" (BLOGOSLAWSKI, 2000, p. 36) 
Os cadernos dos irmãos Hornburg (1950-1968) podem trazer aspectos relevantes acerca da aritmética praticada na escola, o que possibilitou a seguinte indagação: o que revelam os cadernos de classe dos irmãos Hornburg sobre a aritmética do ensino primário, no período 1950-1968?

Nesse contexto, como objetivos, propõe-se analisar os cadernos de classe de matemática do ensino primário dos irmãos Hornburg para compreender a aritmética desenvolvida na escola, bem como discutir sobre os cadernos de classe e as ações de aritmética presentes no contexto da escola.

Justifica-se o estudo, tendo em vista que a análise dos cadernos de classe dos Hornburg possibilita perceber a matemática e as relações que se estabeleceram no cotidiano da escola e que envolveram a aritmética nos saberes elementares propostos para os alunos daquela comunidade

A pesquisa fundamenta-se nos pressupostos da história cultural e é de caráter bibliográfico e documental. Foram analisados 25 cadernos de classe de aritmética dos irmãos Hornburg: Hilário, Anélia, Gisela e Delfino, que estudaram na referida escola no período de 1950 a 1968, e faziam parte da comunidade genuinamente alemã, cuja cultura e tradições foram relevantes na formação da colônia em Jaraguá Sul/SC.

Nas décadas de 1950 e 1960, o ensino no município de Jaraguá do Sul/SC seguia as prescrições do estado de Santa Catarina, que estava organizado rumo ao projeto modernizante da população brasileira. A escola de educação primária, naquele período, tinha um papel preponderante para moldar a sociedade, em harmonia com o pensamento moderno, como uma porta de entrada para o processo de civilidade da população, na formação da personalidade de um novo homem. Nessa construção, as ações educativas dos cadernos de classe dos Hornburg estavam presentes. No estudo dessas ações, concretiza-se a proposta da história cultural que, "centrada no conceito de cultura como objeto de investigação, [...] trata das representações sociais, das práticas culturais e do processo de apropriação, áreas em que a participação dos sujeitos que as vivenciam é fundamental" (VIEIRA, 2015, p. 376).

Do ponto de vista teórico, o estudo se apoiou nos trabalhos de Santos (2002), Teive (2005), Gvirtz (2007), Viñao Frago (2008), Rubio (2008) e Vieira (2015).

A estrutura do artigo compreende: 1) Discussão sobre os cadernos de classe; 2) A escola e os cadernos de classe dos Hornburg; e 3) A aritmética presente nos cadernos dos irmãos Hornburg (1950-1968).

Os resultados apontaram que os cadernos de classe dos irmãos Hornburg trouxeram, em suas folhas amareladas com o tempo, as marcas do ensino intuitivo nas ações de aritmética 
que estavam ligadas a vida dos alunos, da escola e do professor.

\title{
Os Cadernos de classe
}

As transformações da escola ocorrem no tempo e no espaço, afetando os materiais utilizados pelos escolares e promovendo discussões acerca dos sentidos e significados do seu uso no dia a dia da escola. $\mathrm{Na}$ interação escolar dos objetos e indivíduos, o caderno escolar é um material que os escolares utilizam e que se torna um valioso documento histórico das práticas de sala de aula.

O caderno carrega, em suas páginas, a memória escolar dos alunos e professores que os utilizaram nas ações educativas praticadas no cotidiano da escola. Nele estão as marcas das concepções de ensino-aprendizagem do professor, que por sua vez seguem a organização do currículo da escola, que caminha de acordo com a comunidade na qual a escola se insere, manifestando-se na escrita do aluno.

Gvirtz e Larrondo (2008) destacam:

\begin{abstract}
Nessa perspectiva o caderno é considerado um documento, um meio ou suporte físico através do qual se podem visualizar certos conteúdos. Tal documento não é considerado em si mesmo, mas tomado como uma fonte primária neutra para a aproximação de outras questões, permitindo observar que conteúdos se ensinam e como se ensinam (GVIRTZ; LARRONDO, 2008, p.38).
\end{abstract}

Assim, os cadernos de classe são fundamentais para explicar a escrita no contexto da história e da cultura "as fontes primárias, na investigação e na pesquisa, [...] consideradas a matriz explicativa do objeto em estudo, estabelecendo, com tal objeto, uma relação de dependência" (CAMPOS; CURY, 1997, p. 1). Os cadernos escolares dos Hornburg, portanto, são uma fonte primária legítima para a pesquisa, pois foram utilizados por eles na realidade da Escola Municipal de Ensino Fundamental Professor Henrique Heise.

As finalidades dos cadernos são descritas, desde a origem da palavra caderno, como instrumentos, que estão inseridos no contexto da escola. Desse modo, são ferramentas que transformam a vida do aluno e também sofrem transformações, que ficam em suas páginas registrados, com a história das escolas, bem como a história dos sujeitos que deles fazem uso, nas salas de aula. Desde a mais tenra idade as crianças, nos primeiros anos de escolarização, utilizam cadernos escolares para registrar as atividades desenvolvidas no processo de ensinoaprendizagem na escola e em casa.

O caderno de classe, como instrumento de representação da história e cultura escolar e suas transformações é utilizado nos estudos ou pesquisas, em história da educação que envolvem a infância, a família, a escola, a memória, os valores, as disciplinas pedagógicas, a 
escrita entre outros.

Viñao Frago (2008) destaca que:

Os cadernos foram utilizados como fonte para o conhecimento das imagens e representações sociais sobre a infância, a escola, a família, e outros temas similares, como instrumentos de aculturação da escrita; como veículos transmissores de valores e atitudes ou um modo de doutrinação ideológica ou política; como uma forma a mais de trabalho dos alunos junto aos exercícios e folhas soltas. E, ainda, como meio para o estudo do currículo e das diferentes disciplinas e atividades escolares (distribuição do tempo e organização do trabalho em sala de aula, elaboração de uma tipologia de atividades e exercícios, avaliação destes etc.); como uma inovação educativa dentro do movimento internacional da Escola Nova e como instrumento de expressão pessoal subjetiva do aluno (VIÑAO FRAGO, 2008, p.18).

Na Escola Nova, o caderno de classe surgiu como novidade, como meio de inovação, como ferramenta que expressa a sua importância no registro da escrita dos sujeitos que percorreram os bancos escolares.

As imagens vinculadas, os sentidos atribuídos, os signos sociais que revelam a infância, a instituição escolar, a escrita, o contexto familiar, entre outros sentidos e significados podem serem elucidados na escrita dos cadernos de classe. "O caderno é muito mais que um conjunto de folhas de papel onde alunos fazem suas atividades. Esse material assume, no cotidiano escolar, funções e significados importantes que não se encontram descritos e analisados na literatura" (SANTOS, 2002, p.16).

Os cadernos de classe podem ter sentido estrito ou amplo, dependendo do olhar sobre o caderno, a escola, a forma de organização dos sujeitos e seus objetos escolares. Os estudos indicam que os cadernos escolares fazem parte das ações educativas no dia a dia dos alunos e podem elucidar questões sobre a educação.

Essa ferramenta de trabalho do aluno (caderno escolar) carrega marcas na escrita do usuário e produz sentidos diversos de acordo com os valores do observador. As escritas mal traçadas que fogem do rigor da "beleza", a mediação do professor, a aprendizagem, ou a falta dela estão escritas nas páginas dos cadernos de classe.

O caderno escolar é um instrumento de trabalho. Nele o estudante registra a informação escrita e icônica segundo indicações do professor e segundo seu critério. Nele se expressa erros, rasura, aclara e destaca, reflete habilidades cognitivas, estéticas e de motricidade fina. É um espaço próprio apesar da influência indireta do docente. É um produto escolar e cultural ao mesmo tempo em que é produtor de cultura e de escola (ALBARRACÍN, 2015, p.15).

O caderno de classe, presente em diferentes momentos da história e da cultura escolar, é um gerador de cultura na escola. Nele constam erros, acertos, habilidades de coordenação motora fina, ou sua falta.

Como documento das práticas de sala de aula, o caderno faz história e traz histórias na 
interação entre os sujeitos e os objetos utilizados na escola. O caderno de classe carrega em suas folhas, gastadas e amareladas com o tempo, a memória e a cultura escolar de alunos e dos professores de uma instituição de ensino, que o tempo não apaga.

\section{A escola e os cadernos de classe dos Hornburg}

A Escola Municipal de Ensino Fundamental Professor Henrique Heise foi criada pelos imigrantes alemães, que instalaram sua colônia de imigração no bairro Rio da Luz, interior do município de Jaraguá do Sul/SC e divisa com o município de Pomerode/SC.

Em 1958, a escola passou a se chamar Escola Desdobrada Rio da Luz II (JARAGUÁ DO SUL, 2014) e foi nesse ano que Hilário Hornburg, irmão mais velho e um dos autores dos cadernos escolares, completou o $4^{\circ}$ ano na escola.

Os irmãos Hornburg estudaram na escola entre os anos 1950-1968. No ano de 1968, o irmão mais jovem, Delfino Hornburg, completou a $4^{\circ}$ ano do ensino primário.

O Decreto-lei 298, de 18 de novembro de 1946, que regulamentou a Lei Orgânica do Estado de Santa Catarina, para o ensino primário dos catarinenses, dividira o ensino primário em dois grupos: ensino primário fundamental, para crianças de 7 a 12 anos, oferecido em dois cursos sucessivos, o elementar e o complementar (SANTA CATARINA, 1946).

No ensino elementar, com duração de 4 anos, eram realizados os seguintes estudos: leitura, linguagem oral e escrita; iniciação à matemática; geografia e história do Brasil; conhecimentos gerais aplicados à vida social, à educação para a saúde e o trabalho; desenho e trabalhos manuais; canto orfeônico e educação física (SANTA CATARINA, 1946).

O ensino primário complementar, com a duração de 1 ano, podia se estender para 2 anos conforme adequação local, com a finalidade de ampliar a cultura primária dos alunos. $\mathrm{O}$ currículo do ensino primário complementar tinha as mesmas disciplinas que o elementar e, para a ampliação dos conteúdos, estavam acrescidos de aritmética e geometria; geografia geral e história da América; ciências naturais e higiene; conhecimentos das atividades econômicas da região; trabalhos manuais e práticas educativas referentes a economia da região. As meninas aprendiam ainda noções de economia doméstica e de puericultura. Havia, ainda, o curso supletivo primário, destinado para jovens e adultos, com duração de 2 anos de estudos (SANTA CATARINA, 1946).

Em 12 dezembro de 1946, pelo Decreto $n^{\circ} 3.732$, o governador instaurou o Programa de ensino para as escolas de ensino primário do Estado de Santa Catarina, em cumprimento ao Decreto-lei 298 (SANTA CATARINA, 1946). No documento, consta o conteúdo programático da matéria, os objetivos de ensino e sugestões práticas para serem desenvolvidas nas salas de aula das escolas estaduais.

As medidas faziam parte do que constava na reforma do ensino primário público, a 
reforma Elpídio Barbosa $^{2}$ que esteva vigente até os anos 1960, quando os Hornburg estudaram na escola.

A Escola Municipal de Ensino Fundamental Professor Henrique Heise, quando os Hornburg estudaram, era multisseriada, funcionando mais de uma turma de ensino primário juntas (JARAGUÁ DO SUL, 2014). É importante destacar que, na escola as turmas do $1^{\circ}$ ano ficavam dois anos no $1^{\circ}$ ano, ainda que já tivessem atingido os conceitos necessários. No documento Decreto-Lei 298, "o ensino primário abrangerá dois cursos sucessivos o elementar e o complementar, o elementar com duração de 4 anos, o complementar 1 ou dois anos depois do elementar " (SANTA CATARINA, 1946).

O que se observou com relação ao ensino primário na escola foi que acrescentavam um ano a mais no início da escolarização do ensino primário, como complemento do $1^{\circ}$ ano (2 anos de primeiro ano), depois os outros 3 anos completando o ensino primário elementar, em cinco anos de estudos.

Os Hornburg tiveram essa organização de ensino na sua escolarização do ensino primário na Escola de Ensino Fundamental Professor Henrique Heise. Realizaram o ensino elementar em cinco anos, o $1^{\circ}$ ano concluíram em dois anos, os outros 3 anos para o $2^{\circ}, 3^{\circ} 4^{\circ}$ anos.

Observar os cadernos dos irmãos Hornburg para vislumbrar as práticas que envolviam a aritmética no cotidiano da escola, implica perceber neles, as ações desenvolvidas na matemática do ensino elementar do ensino primário público, registradas nos cadernos de classe no tempo e espaço.

\section{A aritmética presente nos cadernos dos irmãos Hornburg}

Os Hornburg estudaram na Escola Municipal de Ensino Fundamental Professor Henrique nos anos de 1950-1968, quando a escola se chamava Escola Desdobrada Rio da Luz II, conforme consta na capa dos cadernos. Foram encontrados, no relicário da família, 25 cadernos de aritmética do ensino primário.

O quadro adiante traz o nome de cada irmão, a quantidade de cadernos de aritmética de cada um deles que foi encontrada na pesquisa, além do ano em que estudaram na Escola Municipal de Ensino Fundamental Professor Henrique Heise.

6 Lei Orgânica do Ensino Primário do Estado de Santa Catarina (Decreto-Lei no 298/46), conhecida como Reforma Elpídio Barbosa. 
Quadro 1: Cadernos de classe de aritmética dos irmãos Hornburg

\begin{tabular}{|l|l|l|l|l|l|}
\hline Nomes & $\begin{array}{c}\text { Número de } \\
\text { cadernos }\end{array}$ & $1^{\circ}$ & $2^{\circ}$ & $3^{\circ}$ & $4^{\circ}$ \\
\hline Hilário Hornburg & 2 & - & - & - & 1958 \\
\hline Anélia Hornburg & 1 & - & - & - & 1959 \\
\hline Gisela Hornburg & 14 & $1961 / 1962$ & 1963 & 1964 & 1965 \\
\hline Delfino Hornburg & 8 & & 1966 & 1967 & 1968 \\
\hline
\end{tabular}

Fonte: organizado pelas autoras, 2017.

Os cadernos de classe dos Hornburg do ensino primário, distribuídos nas classes de $1^{\circ} \mathrm{s}, 2^{\circ} \mathrm{s}, 3^{\circ} \mathrm{s} \mathrm{e} 4^{\circ} \mathrm{s}$ anos do ensino primário elementar, são quadriculados, com encadernamento em brochura, sem especificação das dimensões. A ex-aluna Gisela Hornburg guardou todos os seus cadernos de aritmética e, conforme consta nas capas, a disciplina de matemática era chamada de aritmética. Dos demais irmãos apenas alguns cadernos foram guardados no relicário da família.

Hilário Hornburg é o irmão mais velho. Dele, encontramos dois cadernos de aritmética utilizados no $4^{\circ}$ ano do curso primário. Um com 28 páginas, encapado com papel verde, datado de 24 de maio de 1958, que traz o nome do professor Germano Santos. Outro com o mesmo professor, data de 3 de março de 1958, com 31 páginas e sem capa.

A irmã, Anélia Hornburg, concluiu o $4^{\circ}$ ano em 1959, e dela encontramos um caderno de aritmética, com 31 páginas, da série Companheiro, que, na capa da frente traz a figura de uma jovem de pele branca com vestimentas de pessoa que mora no campo e, na contracapa, o mapa político do Brasil.

De Gisela Hornburg, encontramos a autoria de 14 cadernos de aritmética distribuídos nos $1^{\circ}, 2^{\circ}, 3^{\circ}$ e $4^{\circ}$ anos do ensino primário, utilizados de 1961 a 1965 , ano em que ela finalizou o ensino primário. Sua professora era Darci Franke Velk, conforme consta nas capas. Um dos cadernos, com 26 páginas, tem na capa a figura de uma ponte e a vegetação local, com a mensagem: "caderno para fins escolares", tendo sido fabricado em Indaial-SC, por Heimberg Ehrat \& Ltda. Há também cadernos de 1961 a 1964, com 34 páginas, da série Companheiro, fabricados por Companhia Melhoramentos-SP, que têm na capa ora uma menina com capuz vermelho e sombrinha vermelha; ora um menino saindo do rio, com peixes ancorados numa vara de pau no pescoço; ora uma moça camponesa, como chapéu na cabeça e capim seco na boca, ora um menino de pele branca, consertando um carrinho vermelho, com ferramentas de mecânica. Em todos eles, há um mapa político do Brasil na contracapa. As 
páginas estão amareladas pelo tempo. Verifica-se que a professora Darci Franke Velk foi substituída, em novembro de 1964, pela professora Edi Milnitz.

Os cadernos de classe de aritmética de Delfino Hornburg, nos anos de 1966, 1967 e 1968, apresentam essas mesmas características.

\section{Análise dos cadernos dos Hornburg}

Nas ações pedagógicas do ensino da matemática na primeira metade do século $\mathrm{XX}$, houve uma tendência em se associar os problemas de aritmética apresentados na escola aos problemas com os quais os adultos viessem a se deparar na vida real, "uma abordagem indutiva pela qual o ensino deveria partir do particular para o geral, do conhecido para o desconhecido, do concreto para o abstrato" (SOUZA, 2000, p.12).

O cotidiano do aluno era fundamental para as finalidades da matemática na escola, que estavam relacionadas à vida do aluno. Foi nesse período que os autores dos cadernos de classe, os irmãos Hornburg, estudaram na Escola Municipal de Ensino Fundamental Henrique Heise, anos de 1950-1968, período em que se aumentaram as recomendações para as ações educativas do ensino primário. "O conhecimento pedagógico e as proposições didáticas e metodológicas para o ensino primário ampliaram-se no início do século XX" (SOUZA, 1998, p. 283).

Observando as práticas escolares traduzidas nos cadernos de classe dos irmãos Hilário, Anélia, Gisela e Delfino Hornburg, percebemos a aritmética que se desenvolveu naquela comunidade.

Em relação à matemática, Souza destaca que:

A esse respeito, sobressaem os métodos concretos que precedem as operações escritas e o uso formal e metódico dos algarismos. A utilidade do cálculo mental foi reconhecida desde que praticado sem o caráter abstrato, mas mediante problemas de aplicação usual e próximos da vida das crianças (SOUZA, 2000, p.19)

O conteúdo de ensino da matemática na escola primária deveria estar ligado ao cotidiano do aluno, para que tivesse sentido o que ele fazia na escola. O uso do cálculo mental teve fecundidade, mas deveria ser realizado utilizando o concreto para resolução de problemas. A aritmética articulada na escola propunha ações que envolviam a observação do espaço ao redor do aluno, conforme assinalado na escrita dos cadernos de classe dos irmãos Hornburg.

Nas ações de matemática escritas nos cadernos há marcas dos sujeitos que interagem no cotidiano da escola. Nesse cenário, "destaca-se o caderno escolar como um suporte de escrita portador de marcas de quem ensina e de quem aprende" (LOPES, 2008, 190). 
As atividades que estão registradas nos cadernos dos Hornburg envolvem a resolução de problemas do cotidiano, como plantações de mandioca, de milho, de trigo, laticínios do leite, arrobas de carne, e outros do cotidiano rural, pois a escola ficava numa zona rural. "Resolver problemas é um processo de reorganizar conceitos e habilidades, aplicando-os a uma nova situação, atendendo a um objetivo" (D' AUGUSTINE, 1976, p.17)

Os cadernos dos irmãos eram com grampos e quadriculado para organizar o trabalho com os números e contagens em suas diferentes formas, ordem do valor posicional dos números na realização das operações fundamentais de aritmética, como: soma, subtração, multiplicação e divisão.

Estão registradas, nos cadernos, operações com números decimais que envolviam a medida de manteiga, de banha, tecido, arrobas de carne, feijão, milho, aipim. O sistema monetário, medidas de tempo, de distância, de tecido, sempre envolvendo a resolução de problemas, envolviam as operações fundamentais: adição, subtração, multiplicação e divisão e estão registrados nas páginas dos cadernos. Da mesma forma, problemas de dúzia, meia dúzia, compra e venda de produtos do entorno do aluno.

Observamos, portanto, nas atividades realizadas por Hilário Hornburg, questões relacionadas à vida do aluno, que se manifestam no cotidiano da escola. O cálculo e a solução do problema eram separados por linhas fortes feitas com lápis de cor.

No ano de 1959, o caderno de Anélia Hornburg revela a resolução de problemas de aritmética envolvendo a porcentagem. Numa das páginas, há um desenho da figura humana feito pela aluna e representando a infância da menina, em meio a atividades de aritmética.

No caderno da $1^{\text {a }}$ série do ensino primário de Gisela Hornburg podemos observar desenhos utilizados, como agrupamentos de conjuntos de maçãs e casas. Nas demais folhas do caderno de classe de Gisela, há desenhos, sinalizando o uso de material concreto para a aprendizagem da aritmética.

A utilização de figuras (desenho) e a observação do espaço vivido são ações desenvolvidas no método intuitivo, que considera a aquisição do conhecimento pelos sentidos. Assim, a manipulação de objetos concretos envolve a visão e o tato para chegar aos conhecimentos.

Quanto ao método intuitivo, Remer e Stentzler esclarecem que:

O método intuitivo surgiu na Alemanha no final do século XVIII pela iniciativa de Basedow, Campe e, sobretudo de Pestalozzi. Consistia na valorização da intuição como fundamento de todo o conhecimento, isto é, a compreensão de que a aquisição dos conhecimentos decorria dos sentidos e da observação (REMER; STENTZLER, 2009, p.635). 
O reconhecimento da intuição era a base do conhecimento, segundo o método intuitivo. As mudanças do ensino da aritmética intuitivo modificariam a escola sem qualidade, para uma escola com eficiência e com materiais concretos para a relação do ensino com a vida cotidiana do aluno. Essas ideias, que estavam sendo experimentadas nas ações de matemática, constroem uma interpretação de que o passado da aritmética no ensino primário nada acrescentava ao sujeito.

Valente revela que:

A chegada do ideário do ensino intuitivo, como experimental e concreto, constrói uma representação do passado do ensino de Aritmética no primário, profundamente negativa. Trata-se de um ensino abstrato, com uso quase exclusivo de processos de memorização, sem utilidade. Também ela, a Aritmética, imersa nessa escola ineficiente, deve ser transformada. Ensinada de outro modo, com materiais onde o ensino possa ser o mais concreto possível (VALENTE, 2012, p.1422).

Nas ideias pedagógicas do método intuitivo, as ações de aritmética realizadas com manipulação dos materiais concretos, trouxeram a perspectiva de combater a desarticulação do ensino com a realidade.

Gisela Hornburg completou a sua escolarização do $4^{\circ}$ ano primário com as atividades de aritmética que estavam relacionadas ao cotidiano dos alunos: a escola ficava numa área rural e os alunos trabalhavam com unidades agrárias.

As finalidades da aritmética na modernidade na história e a cultura da disciplina de matemática se articularam de modo que a cultura escolar embutiu normas para os saberes elementares matemáticos, entre os anos 1950 e 1968. As mudanças da aritmética movem os conhecimentos de compreender a história das disciplinas escolares. Assim, a metodologia desenvolvida na aritmética no período compreendido de 1950/1968, mobiliza para a resolução de problemas que estavam no cotidiano do aluno de modo vivo e que pudessem perceber a sua realidade, no contexto das ações que envolviam números e contagens.

Atividades envolvendo situações de plantação, também faziam parte do currículo da escola, observados no caderno de Gisela Hornburg, em 1965, que revelam a organização da comunidade que era localizada numa área rural e revela o método intuitivo de observação da realidade dos alunos.

Os cadernos de Delfino Hornburg, que completou o $4^{\circ}$ ano em 1968, revelam a aritmética com problemas que envolviam o sistema monetário e a quantidade de materiais na construção das casas. Também se observa a quantidade de funcionários, a medida de tempo e o número de pessoas na construção da obra, sempre envolvendo problemas cotidianos da comunidade escolar. 
Enfim, em todos os cadernos dos irmãos Hornburg que foram analisados, pode-se observar a preocupação de envolver a aprendizagem da aritmética em ações que estivessem ligadas ao contexto local da escola.

\section{Considerações finais}

Ao analisar os cadernos de classe de aritmética do ensino primário dos irmãos Hornburg, compreendeu-se que a matemática desenvolvida na escola estava baseada no método intuitivo, que predominou na educação brasileira entre o final do século XIX e meados do século XX. As ações de aritmética vividas pelos irmãos Hornburg, registradas nas folhas dos seus cadernos de classe, e as práticas matemáticas eram desenvolvidas com ideias da Escola Nova.

Essas práticas abrangiam o concreto e faziam parte do método intuitivo, que valorizava a observação e a análise da realidade do aluno, como as práticas de matemáticas envolviam problemas de plantio, colheita e outras ações que envolviam problemas de aritmética e a zona rural.

Nas páginas dos cadernos de classe dos irmãos estão escritas as ações que fazem parte das memórias de sujeitos e as ações educativas presentes no contexto da escola municipal de ensino fundamental Professor Henrique Heise.

Observou-se o estudo do cotidiano do aluno nas atividades de aritmética, com desenhos que indicavam o contexto da própria comunidade escolar, percebendo-se que a educação matemática acompanhava a renovação das ideias pedagógicas no contexto histórico da época.

Em última análise, os cadernos de classe dos irmãos Hornburg trazem a aritmética que foi praticada na escola, entre 1950 e 1958, com base no método intuitivo, relacionada ao cotidiano dos alunos. Como documentos históricos da cultura escolar, esses cadernos carregam memórias, histórias e revelam uma cultura que se articulou na comunidade num determinado tempo e história.

\section{Referências}

ALBARRACÍN, Doris Carmenza Monroy Saberes, sentidos e representações cotidianas; em cadernos escolares de professoras em formação (2011-2013). 116f .2015. Dissertação (Mestrado em Educação) - Pontifícia Universidade Católica do Paraná, Curitiba, 2009.Disponível em: $<$ http://www.biblioteca.pucpr.br/tede/tde_busca/arquivo.php?codArquivo=3021 >. Acesso em, 31 jan.2017. 
BLOGOSLAWSKI, Ilson Paulo Ramos. A escola alemã no Alto Vale do Itajaí: Colônia Matador, Bella Alliança - 1892-1930. 2000. 159 f. Dissertação (Mestrado em Educação) - Universidade Federal de Santa Catarina, (UFSC/UNIPLAC-LAGES (SC)). Florianópolis, 2000.

CAMPOS, Edson Nascimento; CURY, Maria Zilda Ferreira. Fontes primárias: saberes em movimento. Rev. Fac. Educ., São Paulo, vol. 23, n. 1-2, p.311-323, jan. /dez, 1997. doi.org/10.1590/S0102-25551997000100016.

CAMARGO, Felipe Côrte Real de. Do tombamento à chancela: o estabelecimento do bairro Rio da Luz como paisagem cultural brasileira e seu contexto urbanístico (Jaraguá do Sul 2007-2013). 2013. 140 f. Dissertação (Mestrado em Educação) - Universidade Federal de Santa Catarina, Florianópolis, 2013.

CECCHETTI, Élcio; SANTOS, Ademir. Valdir dos. Imigração alemã, luteranismo e a criação de escolas no sul do Brasil. In: Congresso Brasileiro de História da Educação, 7, 2013, Cuiabá. Anais... Cuiabá: UFMT, 2013. v. 1. p. 1-15. Disponível em: $\langle$ http://sbhe.org.br/novo/congressos/cbhe7/>. Acesso em: 7 fev. 2017.

CHARTIER, Roger. "Cultura Popular": revisitando um conceito historiográfico. Estudos Históricos, Rio de Janeiro, voI. 8, n 16, p. 179-192, 1995.

D' AUGUSTINE, Charles H. Métodos modernos para o ensino da matemática. (Trad.) PERES, Maria Lúcia F.E. Ao livro técnico, Rio de Janeiro, $2^{\mathrm{a}}$ edição, 1976.

GVIRTZ, Silvina. Del curriculum prescripto al curriculum enseñado: uma mirada a los cuadernos de clase. Buenos Aires: AIQUE, 2007.

GVIRTZ, Silvina; LARRONDO, Marina. Os cadernos de Classe como fonte primária de pesquisa: alcances e limites teóricos e metodológicos para sua abordagem. In: MIGNOT, Ana Chrystina Venâncio. (Org.). Cadernos à vista: escola, memória e cultura escrita. Rio de Janeiro: Eduerj, 2008. p. $35-48$

JARAGUÁ DO SUL. Documento de Orientações Gerais Henrique Heise. 37f. Jaraguá do Sul, 2014.

JARAGUÁ DO SUL, Prefeitura. Síntese da história da cidade. Disponível em <http://portal.jaraguadosul.com.br/sintese-da-historia-da-cidade-jaragua-do-sull >. Acesso em: 04 fev.2017. REVER NORMAS - Não foi utilizado no texto, embora sobrou uma referência : JARAGUÁ DO

SUL,

2016 ,

p.02.

LOPES, Isa Cristina da Rocha Lopes. Cadernos escolares: memória e discurso em marca de correção. In: MIGNOT, Ana Chrystina Venâncio. (Org.). Cadernos à vista: escola, memória e cultura escrita. Rio de Janeiro: Eduerj, 2008. p. 187-2004.

MONTEIRO, Jaecyr. Nacionalização do Ensino em Santa Catarina 1930 - (1940.1979).167 f. Dissertação (Mestrado em história) -Universidade Federal de Santa Catarina, Florianópolis, 1979.

REMER, Maísa Milènne Zarur; STENTZLER, Márcia Marlene. Método intuitivo: Rui Barbosa e a preparação para a vida completa por meio da educação integral. In: Congresso Nacional de EducaçãoEDUCERE, 9, 2009, Curitiba. Anais... Curitiba: Pontifícia Universidade Católica do Paraná-PUCPR, 2009.p.6334-6345. http://www.pucpr.br/eventos/educere/educere2009/anais/pdf/2908_1161.pdf .Acesso em:12 mar. 2017. 
RENK, Valquiria Elita. Educação de imigrantes alemães em Curitiba. Diálogo Educacional, Curitiba, v. $5, \quad$ n.14, p.101-111, jan. /abr. $2005 . \quad$ Disponível em: 〈http://www.sbhe.org.br/novo/congressos/cbhe3/Documentos/Individ/Eixo6/217.pdf>. Acesso em: 27 fev. 2017.

RUBIO, Ana Chrystina Venâncio. A estética e as ilustrações nos cadernos escolares: o caso de uma escola de meninas na Espanha franquista. In: MIGNOT, Ana C. V. (Org.). Cadernos à vista: Escola, memória e cultura escrita. Rio de Janeiro: Eduerj, 2008. p. 239-256

SANTA CATARINA. Decreto-Lei $\mathbf{n}^{\mathbf{0}} 298$ de 18 de novembro de 1946. Lei Orgânica do Ensino Primário. Florianópolis, 1946. Disponível em: $<$ https://repositorio.ufsc.br/handle/123456789/122146 $>$. Acesso em: 01 jan. 2017.

SANTA CATARINA, Secretaria da Justiça, Educação e Saúde. Decreto-Lei no 3.73212 de dezembro de 1946. Programa para os estabelecimentos do ensino primário. Florianópolis, 1946. Disponível em: <https://repositorio.ufsc.br/handle/123456789/99620?show=full> . Acesso em: 01 jan. 2017.

SANTOS, Anabela Costa e. Cadernos escolares na primeira série do ensino fundamental: funções e significados. 2002,152 f. Dissertação (Mestrado em Psicologia) - Instituto de Psicologia Universidade de São Paulo, São Paulo, 2002. Disponível em: $<$ http://www.teses.usp.br/teses/disponiveis/47/47131/tde-08052006170850/publico/DissertacaoSANTOS2002.pdf $>$. Acesso em: 31 jan.2017.

SOUZA, Rosa Fátima de Inovação educacional no século XIX: A construção do currículo da escola primária no Brasil Cadernos Cedes, ano 20, $n^{\circ}$ 51, p. 9-28, novembro, 2000.

SOUZA, Rosa Fátima de. Templos de civilização: a implantação da escola primária graduada no estado de São Paulo, 1890-1910. UNESP. São Paulo, 1988.

TEIVE, Gladys Mary Ghizoni. "Uma vez normalista, sempre normalista": a presença do método de ensino intuitivo ou lições de coisas na construção de um habitus pedagógico (escola normal catarinense 1911-1935). 2005. 290 f. Tese (Doutorado em Educação) -Universidade Federal do Paraná, 2005. Disponível em: 〈www.anped.org.br/sites/default/files/gt081450int.pdf >. Acesso em: 25 jan. 2017.

VALENTE, Wagner Rodrigues. O que é número? Produção, circulação e apropriação da Matemática Moderna para crianças. Bolema: Boletim de educação matemática. Rio Claro, 2012, p. 1417-1441. Disponível em: http://www.scielo.br/scielo.php?script=sci arttext\&pid=S0103-636X2012000400014 . Acesso em: 13 fev. 2017.

VIEIRA, Alboni Marisa Dudeque Pianovski. A história cultural e as fontes de pesquisa Revista HISTEDBR On-line, Campinas, $\mathrm{n}^{\circ}$ 61, p. 367-378, mar. 2015. Disponível em:<periodicos.sbu.unicamp.br/ojs/index.php/histedbr/article/view/8640533>. Acesso em: 25 fev. 2017.

VIÑAO FRAGO, Antonio. Os cadernos escolares como fonte histórica: aspectos metodológicos e historiográficos. In: MIGNOT, Chrystina Venâncio. (Org.). Cadernos à vista: escola, memória e cultura escrita. Rio de Janeiro: Eduerj, 2008, p.15-33

Recebido em 22/04/2017 - Aceito em 31/10/2017 